\title{
Comparison of Association between Cervical Spine and Face in Subjects with Vertical and Horizontal Growth Pattern: An in vitro Study using Lateral Cephalogram
}

\author{
${ }^{1}$ Deoashish D Gupta, ${ }^{2}$ Priyanka Niranjane, ${ }^{3}$ Narendra Sharma, ${ }^{4}$ Sunita Shrivastav, ${ }^{5}$ Ranjit H Kamble, ${ }^{6}$ Rakesh Nathani
}

\begin{abstract}
Purpose: The purpose of this study was to analyze and compare the association between cervical spine and face in subjects with vertical and horizontal growth pattern using lateral cephalogram.
\end{abstract}

Materials and methods: Lateral cephalograms of 75 subjects between ages of 18 and 35 years were taken and analyzed. The study sample was divided into three groups of 25 individuals each; i.e., vertical growth pattern (gonial angle $>125^{\circ}$ ); horizontal growth pattern (gonial angle $<121^{\circ}$ ); and control group with average growth pattern (gonial angle $123^{\circ}$ $\pm 2.5^{\circ}$ ). The relation between upper cervical vertebrae and face was compared between three groups by taking linear measurements.

Results: A statistically significant difference was observed in vertical dimensions of second cervical vertebra when it was correlated with anterior cranial base, maxilla and mandible in adults having horizontal and vertical growth pattern as compared to individuals with average growth pattern. Linear vertical measurements between maxilla to cervical spine and mandible to cervical spine were less in horizontal growth pattern as compared to vertical and average growth pattern. The $p$-value of $\mathrm{SCV}_{2}-0.001, \mathrm{GoCV}_{2}-0.405$, and $\mathrm{PmCV}_{2}-0.001$ showed significant results within intergroups.

Conclusion: It can be concluded that there exists an association between the morphology of the cervical vertebrae and the vertical and horizontal skeletal growth patterns.

Keywords: Cervical vertebrae, Growth pattern, $\mathrm{CV}_{2}, \mathrm{CV}_{3}, \mathrm{CV}_{4}$. How to cite this article: Gupta DD, Niranjane P, Sharma N, Shrivastav S, Kamble RH, Nathani R. Comparison of Association between Cervical Spine and Face in Subjects with Vertical and Horizontal Growth Pattern: An in vitro Study using Lateral Cephalogram. World J Dent 2016;7(2):73-77.

Source of support: Nil

Conflict of interest: None

\footnotetext{
${ }^{1,6}$ Senior Resident, ${ }^{2}$ Reader, ${ }^{3}$ Associate Professor

${ }^{4}$ Professor and Head, ${ }^{5}$ Professor

${ }^{1-6}$ Department of Orthodontics, Sharad Pawar Dental College Datta Meghe Institute of Medical Sciences, Wardha, Maharashtra India

Corresponding Author: Deoashish D Gupta, Senior Resident Department of Orthodontics, Sharad Pawar Dental College, Datta Meghe Institute of Medical Sciences, Wardha, Maharashtra, India Phone: +919096425397, e-mail: deoashish.g@gmail.com
}

\section{INTRODUCTION}

The cervical spine has been an area of interest in orthodontics for several reasons. A number of authors have described the association between head posture and craniocervical morphology that may affect the pattern of craniofacial growth. Various studies in the literature have suggested that the morphology of cervical vertebrae seems to be affected by head posture, age, congenital anomalies and skeletal growth pattern. The existence of a relationship between head posture and craniofacial structure was first demonstrated by Solow and Tallgren ${ }^{1}$ in 1976 who concluded that a more downward head posture was associated with a more horizontal and an extended head posture was associated with a more vertical growth pattern of the mandible. Kylamarkula and Huggare ${ }^{2}$ found that the horizontal and vertical dimensions of first cervical vertebra $\left(\mathrm{CV}_{1}\right)$; atlas, related directly with head posture, cranial base angulation, mandibular shape and growth. Watanabe et $\mathrm{al}^{3}$ in 2010 has described the morphology of cervical vertebra in subjects with different sagittal jaw relationships using cone-beam computed tomography. The cervical vertebral column has also been used as a reference structure for assessing natural head position on lateral cephalograms. In the past three decades, association between the cervical vertebral maturation (CVM) and maxillomandibular growth has received increasing attention. Salagnac et al reported that vertical growth of cervical spine; mandible and upper face were anatomically and physiologically correlated. ${ }^{5}$

Very few studies in the literature have described the existence of relationship between cervical spine and growth pattern. Thus, the purpose of present study was to investigate whether there is a correlation between the morphology of cervical spine and face in individuals with various growth patterns (average, horizontal and vertical) using two-dimensional (2D) imaging technique, i.e., lateral cephalogram. It was hypothesized that there may be correlation between head and spine posture and growth of jaw bases. The head posture alters the muscle function and orientation and so may indirectly contribute to the altered growth of jaw bases. 


\section{MATERIALS AND METHODS}

The present study was conducted at Sharad Pawar Dental College and Hospital, Wardha, Maharashtra. Lateral cephalograms of 75 subjects between 18 and 35 years age (40 males and 35 females) were taken and analyzed. The cephalometric parameters used for selection of the study sample were enlisted in Table 1.

Based on the parameters, the sample was divided into three groups, i.e., horizontal vertical and average growth pattern (control group) consisting of 25 individuals each. The individuals selected for the study sample had acceptable occlusions, were nonsyndromic with no systemic muscle or joint disorders and had no history of previous orthodontic treatment.

\section{ANALYSIS OF MORPHOLOGY AND GROWTH}

The first to fifth cervical vertebrae which are normally seen in the lateral skull radiograph were assessed. The following reference points and lines were identified: nasion $(\mathrm{N})$, orbitale $(\mathrm{Or})$, spinal-point $(\mathrm{Sp})$, gnathion $(\mathrm{Gn})$, sella $(\mathrm{S})$, basion $(\mathrm{Ba})$, condylion $(\mathrm{Cd})$, porion $(\mathrm{Po})$, pterygomaxillary $(\mathrm{Pm})$, gonion (Go), SN-line (SN), Frankfort horizontal plane (FH), mandibular plane (MP), tangential mandibular line $\left(\mathrm{ML}_{1}\right)$, second cervical vertebra $\left(\mathrm{CV}_{2}\right)$, third cervical vertebra $\left(\mathrm{CV}_{3}\right)$, and fourth cervical vertebra $\left(\mathrm{CV}_{4}\right)$. Most points and lines are well known; only a few need explanation:

Second cervical vertebra was defined as the lower and anterior most point on inferior border of the body of the second cervical vertebra, $\mathrm{CV}_{3}$ as the lower and anterior most point on inferior border of the third cervical vertebra, and $\mathrm{CV}_{4}$ as the lower and anterior most point on inferior border of the body of the fourth cervical vertebra. Each cephalogram was manually traced and measured twice. Tolerance limits of $1 \mathrm{~mm}$ and $1^{\circ}$ were set for the difference between the first and second observations of linear and angular measurements.

On cephalogram, angle FH-SN was measured and designated angle alpha $(\alpha)$ (Fig. 1). On subsequent cephalograms, line was constructed through $\mathrm{S}$ at angle

Table 1: Cephalometric parameters used for selection of the study sample

\begin{tabular}{|c|c|c|c|}
\hline $\begin{array}{l}\text { Sl. } \\
\text { no. }\end{array}$ & $\begin{array}{l}\text { Cephalometric } \\
\text { parameter }\end{array}$ & $\begin{array}{l}\text { Subjects with } \\
\text { horizontal growth } \\
\text { pattern }\end{array}$ & $\begin{array}{l}\text { Subjects with } \\
\text { vertical growth } \\
\text { pattern }\end{array}$ \\
\hline 1 & Gonial angle & $<121^{\circ}$ & $>135^{\circ}$ \\
\hline 2 & $\begin{array}{l}\text { Mandibular plane } \\
\text { angle (FH-Me) }\end{array}$ & $<17^{\circ}$ & $>28^{\circ}$ \\
\hline 3 & Basal plane angle & $<15^{\circ}$ & $>30^{\circ}$ \\
\hline 4 & Jaraback ratio & $<65 \%$ & $>75 \%$ \\
\hline 5 & $\begin{array}{l}\text { Lower anterior } \\
\text { facial height }\end{array}$ & $<58 \mathrm{~mm}$ & $>72 \mathrm{~mm}$ \\
\hline
\end{tabular}

to $\mathrm{SN}$ equivalent to angle $\alpha$ which was designated as $\mathrm{FH}$ estimated (FHe). Points within upper cervical spine $\left(\mathrm{CV}_{2}\right.$, $\mathrm{CV}_{3}, \mathrm{CV}_{4}$ ), maxilla (Pm) and mandible (Go) were projected on line perpendicular to FHe and extended inferiorly from S. Vertical dimension of upper cervical spine (variable 1 Table 2), vertical positions of cervical vertebrae (variables 2-4 of Table 2) were measured along line extended inferiorly from S. Linear dimensions were measured to evaluate the variations in vertical dimension of the cervical vertebrae relative to cranial base, maxilla and mandible in adults with vertical and horizontal growth pattern. These values were then compared with average growth pattern.

\section{STATISTICAL METHOD}

Descriptive and analytical statistics were done. The Kolmogorov-Smirnov test was used to check normality of data and one-way ANOVA with Scheffe's post hoc test was used to check the mean differences between groups.

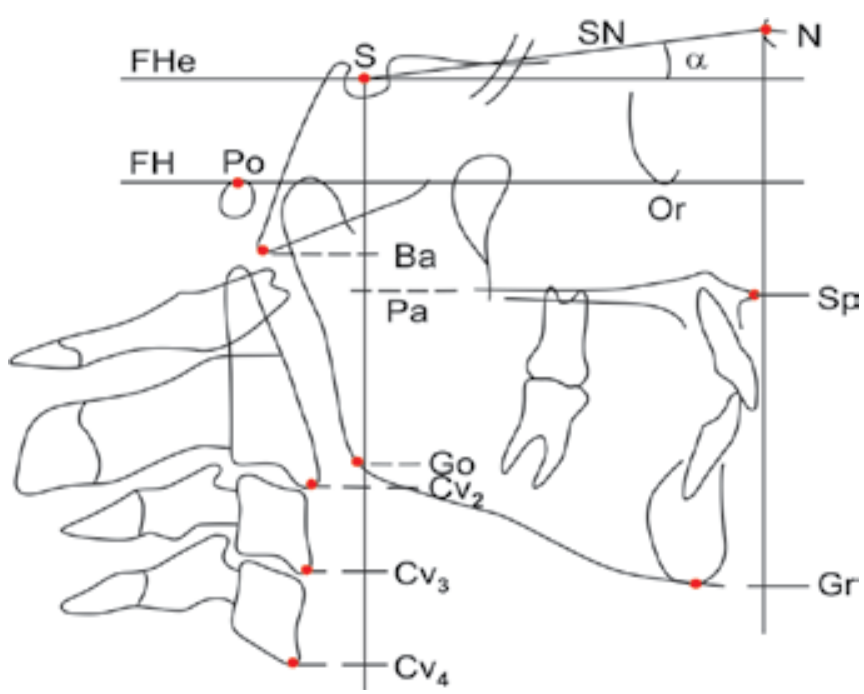

Fig. 1: Reference points and lines [Angle FH-SN was measured and designated angle alpha $(\alpha)$. On subsequent cephalograms, line was constructed through $S$ at angle to $\mathrm{SN}$ equivalent to angle $\alpha$ which was designated as $\mathrm{FH}$ estimated $(\mathrm{FHe})$. Points within upper cervical spine $\left(\mathrm{CV} 2, \mathrm{CV}_{3}, \mathrm{CV}_{4}\right)$, maxilla $(\mathrm{Pm})$ and mandible (Go) were projected on line perpendicular to $\mathrm{FHe}$ and extended inferiorly from $\mathrm{S}$ ]

Table 2: Definitions of variable

\begin{tabular}{llll}
\hline Sl. & Cephalometric & $\begin{array}{l}\text { Subjects with } \\
\text { horizontal growth } \\
\text { nottern }\end{array}$ & $\begin{array}{l}\text { Subjects with } \\
\text { vertical growth } \\
\text { pattern }\end{array}$ \\
\hline 1 & Gonial angle & $<121^{\circ}$ & $>135^{\circ}$ \\
2 & $\begin{array}{l}\text { Mandibular plane } \\
\text { angle (FH-Me) }\end{array}$ & $<17^{\circ}$ & $>28^{\circ}$ \\
3 & Basal plane angle & $<15^{\circ}$ & $>30^{\circ}$ \\
4 & Jaraback ratio & $<65 \%$ & $>75 \%$ \\
5 & Lower anterior & $<58 \mathrm{~mm}$ & $>72 \mathrm{~mm}$ \\
& facial height & & \\
\hline
\end{tabular}


Comparison of Association between Cervical Spine and Face in Subjects with Vertical and Horizontal Growth Pattern

Table 3: Mean, standard error and standard deviations for the variables in the horizontal, vertical, and average growth pattern groups

\begin{tabular}{llll}
\hline Sl. & $\begin{array}{l}\text { Cephalometric } \\
\text { no. }\end{array}$ & $\begin{array}{l}\text { Subjects with } \\
\text { porizontal growth } \\
\text { pattern }\end{array}$ & $\begin{array}{l}\text { Subjects with } \\
\text { vertical growth } \\
\text { pattern }\end{array}$ \\
\hline 1 & Gonial angle & $<121^{\circ}$ & $>135^{\circ}$ \\
2 & $\begin{array}{l}\text { Mandibular plane } \\
\text { angle (FH-Me) }\end{array}$ & $<17^{\circ}$ & $>28^{\circ}$ \\
& Basal plane angle & $<15^{\circ}$ & $>30^{\circ}$ \\
4 & Jaraback ratio & $<65 \%$ & $>75 \%$ \\
5 & Lower anterior & $<58 \mathrm{~mm}$ & $>72 \mathrm{~mm}$ \\
& facial height & & \\
\hline
\end{tabular}

Table 4: Intergroup correlation between variables

\begin{tabular}{llll}
\hline Sl. & $\begin{array}{l}\text { Cephalometric } \\
\text { parameter }\end{array}$ & $\begin{array}{l}\text { Subjects with } \\
\text { horizontal growth } \\
\text { pattern }\end{array}$ & $\begin{array}{l}\text { Subjects with } \\
\text { vertical growth } \\
\text { pattern }\end{array}$ \\
\hline 1 & Gonial angle & $<121^{\circ}$ & $>135^{\circ}$ \\
2 & $\begin{array}{l}\text { Mandibular plane } \\
\text { angle (FH-Me) }\end{array}$ & $<17^{\circ}$ & $>28^{\circ}$ \\
3 & Basal plane angle & $<15^{\circ}$ & $>30^{\circ}$ \\
4 & Jaraback ratio & $<65 \%$ & $>75 \%$ \\
5 & $\begin{array}{l}\text { Lower anterior } \\
\text { facial height }\end{array}$ & $<58 \mathrm{~mm}$ & $>72 \mathrm{~mm}$ \\
\hline
\end{tabular}

Table 5: Correlation of variables between intergroups

\begin{tabular}{|c|c|c|c|c|c|c|c|c|}
\hline \multirow[b]{2}{*}{ SI. no. } & \multirow[b]{2}{*}{ Item } & & & \multirow{2}{*}{$\begin{array}{c}\text { Mean } \\
\text { difference }\end{array}$} & \multirow[b]{2}{*}{ Std. error } & \multirow[b]{2}{*}{ Sig. } & \multicolumn{2}{|c|}{$95 \% \mathrm{Cl}$} \\
\hline & & \multicolumn{2}{|c|}{ Groups } & & & & Lower & Upper \\
\hline \multirow[t]{3}{*}{1} & $\mathrm{BaCV}_{4}$ & Vertical & Horizontal & 10.60 & 2.23 & $0.000^{*}$ & 5.02 & 16.17 \\
\hline & & Vertical & Average & 3.32 & 2.23 & 0.336 & -2.25 & 8.89 \\
\hline & & Horizontal & Average & -7.28 & 2.23 & $0.007^{*}$ & -12.85 & -1.70 \\
\hline \multirow[t]{3}{*}{2} & $\mathrm{SCV}_{2}$ & Vertical & Horizontal & 8.28 & 1.63 & $0.000^{*}$ & 4.18 & 12.37 \\
\hline & & Vertical & Average & -0.68 & 1.63 & 0.917 & -4.77 & 3.41 \\
\hline & & Horizontal & Average & -8.96 & 1.63 & $0.001^{*}$ & -13.05 & -4.86 \\
\hline \multirow[t]{3}{*}{3} & $\mathrm{SCV}_{3}$ & Vertical & Horizontal & 9.84 & 1.83 & $0.001^{*}$ & 5.25 & 14.42 \\
\hline & & Vertical & Average & -1.20 & 1.83 & 0.808 & -5.78 & 3.38 \\
\hline & & Horizontal & Average & -11.04 & 1.83 & $0.001^{*}$ & -15.62 & -6.45 \\
\hline \multirow[t]{3}{*}{4} & $\mathrm{SCV}_{4}$ & Vertical & Horizontal & 10.28 & 2.09 & $0.001^{*}$ & 5.04 & 15.51 \\
\hline & & Vertical & Average & -10.28 & 2.09 & $0.001^{*}$ & -15.51 & -5.04 \\
\hline & & Horizontal & Average & -11.64 & 2.09 & $0.001^{*}$ & -16.87 & -6.40 \\
\hline \multirow[t]{3}{*}{5} & $\mathrm{GoCV}_{2}$ & Vertical & Horizontal & 3.64 & 3.67 & 0.615 & -5.55 & 12.83 \\
\hline & & Vertical & Average & 4.76 & 3.67 & 0.437 & -4.43 & 13.95 \\
\hline & & Horizontal & Average & 1.12 & 3.67 & 0.955 & -8.07 & 10.31 \\
\hline \multirow[t]{3}{*}{6} & $\mathrm{PmCV}_{2}$ & Vertical & Horizontal & 5.60 & 2.23 & $0.050^{*}$ & 0.03 & 11.19 \\
\hline & & Vertical & Average & -5.48 & 2.23 & $0.056^{*}$ & -11.07 & 0.11 \\
\hline & & Horizontal & Average & -11.08 & 2.23 & $0.001^{*}$ & -16.67 & -5.48 \\
\hline
\end{tabular}

\section{OBSERVATIONS AND RESULTS}

The mean linear measurement of $\mathrm{SCV}_{2}, \mathrm{GoCV}_{2}$ and $\mathrm{PmCV}_{2}$ showed significant difference between the three groups. It was $76.08 \mathrm{~mm}( \pm 1.27), 8.28 \mathrm{~mm}( \pm 2.41)$, and $59.40 \mathrm{~mm}( \pm 2.03)$ respectively in vertical. It was $67.80 \mathrm{~mm}$ $( \pm 1.10), 4.64 \mathrm{~mm}( \pm 0.76)$ and $53.80 \mathrm{~mm}( \pm 1.33)$ respectively in horizontal and $76.76 \mathrm{~mm}( \pm 1.04), 3.52 \mathrm{~mm}( \pm 0.44)$ and $64.88 \mathrm{~mm}( \pm 0.94)$ in control or average subjects (Table 3 ).

The mean linear measurement of $\mathrm{SCV}_{3}$ showed significant difference. It was $93.36 \mathrm{~mm}( \pm 1.25)$ in vertical and $83.52( \pm 1.28)$ in horizontal group. The skeletal horizontal pattern and skeletal vertical pattern subjects showed a significant increase in the height of the vertebrae body of C3.

The mean linear measurement of $\mathrm{BaCV}_{4}$ and $\mathrm{SCV}_{4}$ showed significant difference between three groups. It was $71.48( \pm 1.10)$ and $108.92( \pm 1.41)$ in vertical group; $60.88( \pm 2.08)$ and $98.64( \pm 1.45)$ in horizontal group and $68.16( \pm 1.33)$ and $110.28( \pm 1.58)$ in average group respectively (Tables 4 and 5).

\section{DISCUSSION}

An improved understanding of the association between head posture and craniocervical morphology is essential for diagnosis and treatment of morphological and functional disturbances in the craniofacial region. In the present study, an attempt was made to find a correlation between the morphology of cervical spine and face in individuals with different growth patterns using lateral cephalogram.

When the vertical dimensions between $\mathrm{CV}_{2}$ with cranial base, maxilla and mandible was compared in all the three different growth pattern, it was found that these linear measurements were less statistically significant in horizontal and more in vertical growth pattern when compared with average growth pattern. There are no studies in the literature correlating the third cervical vertebra with facial variables. When linear measurements between $\mathrm{CV}_{3}$ and $\mathrm{CV}_{4}$ with cranial base were made it was found that this distance was more in vertical and 
less in horizontal growth pattern. This finding was also statistically significant. These findings are in accordance with the study by Karlsen AT who concluded that a mutual relationship exists between vertical growth of the upper cervical spine and the face, especially the lower face. An explanation for this association was given by Huggare J.6

The effects of muscle thickness on bone morphology can be explained Wolff's law (Dibbets, 1992). Which states that the internal structure and shape of bone is closely related to muscle function (Wolff, 1870). ${ }^{7}$ Based on the results of EMG and bite-force studies, it has been suggested that long-face individuals have weaker muscles (Moller, 1966; Ringqvist, 1973a; Ingervall and Thilander, 1974; Ingervall, 1976; Sassouni, 1969; Finn, 1978; Proffit et al, 1983). Thus, it can be correlated that weaker muscular pattern have less pull effect of these ligaments which are connecting the face with cervical vertebrae.

The $C_{2}$ is the highest and largest of the cervical vertebra. The odontoid process, or dens of the $\mathrm{CV}_{2}$ runs approximately parallel to the mandibular ramus. The vertical position of Go might hold the key to the vertical development of the face-particularly in the development of the lower face. In high-angle subjects, a long $\mathrm{GoCV}_{2}$ may give rise to a short-lower posterior facial height. ${ }^{9,10}$

Houston proposed growth of the cervical vertebrae as main determinant of increase in anterior facial height and developed a model in which vertical increase of the cervical spine elevated the cranium in relation to the shoulder girdle (clavicle, sternum, scapula). The growth and stretch of the muscles and fascia passing between the cranium, mandible, hyoid bone, and shoulder girdle were associated with the descent of the symphysis and hyoid bone relative to the cranial base. ${ }^{11}$

Dimensions of $C_{1}$ as well as head and neck posture are interrelated with craniofacial morphology, including the cranial $^{9-11}$ upper airway space, ${ }^{12}$ occlusion, ${ }^{13}$ and temporomandibular disorders. ${ }^{13}$

Several 2D studies have evaluated variations in the dimensions of cervical vertebrae as related with skeletal malocclusions. ${ }^{14}$

In an earlier cross-sectional study - a remarkable similarity in facial form was found between subjects with a large craniocervical angle and subjects with a large mandibular plane inclination, and also between subjects with a small craniocervical angle and subjects with a small mandibular plane angle. This suggested that craniocervical angulation might be particularly related to mandibular development, however, cross-sectional correlation studies do not permit inferences regarding cause-and-effect relationships. ${ }^{15}$

An explanation for the associations between the morphologic deviations in the cervical vertebral column and the craniofacial morphology including could be found in the early embryogenesis. Because the notochord determines the development of the body of the cervical vertebra and also of the basilar part of the occipital bone, which is the posterior part of the cranial base angle. Since the cranial base is connected to the cervical vertebral column by the notochord in early embryogenesis, and the jaws are attached to the cranial base, the cranial base could be the developing link between the cervical vertebral column and the jaws. ${ }^{16}$

This suggests that severe vertical skeletal malocclusions are associated with an increase in the vertical dimension of the axis or second cervical vertebrae.

In the present study, an association was seen between morphological deviations of the upper cervical vertebrae $\left(C_{2}-C_{4}\right)$ and the skeletal growth pattern (vertical and horizontal growth pattern). This indicates that the morphological deviations of the upper cervical vertebrae are associated with malformation of the jaws and also have an association with the craniofacial morphology.

However, the results should be interpreted with caution due to the cross-sectional nature of the study which do not permit inferences regarding cause and effect relationship.

\section{CONCLUSION}

It can be concluded that there is an association between the morphology of the cervical vertebrae and the vertical and horizontal skeletal growth patterns. The results of our study indicate that there is a significant association between the morphology of the cervical vertebrae and the growth pattern of the mandible.

\section{ACKNOWLEDGMENTS}

Authors would like to thanks Dr. Priyanka Niranjane and Dr. Ashish Jaiswal for supporting and analyzing the study material. Special gratefulness are extended to my teachers Dr. R Kamble, Dr. S Shrivastav, Dr. Narendra Sharma (my guide) and Dr. Rakesh Nathani for their support and guidance throughout this study. Author acknowledges the immense help received from the scholars whose articles are cited and included in references of this manuscript. The authors are grateful to authors/editors/publishers of all those articles, journals and books from where the literature for this article has been reviewed and discussed.

\section{REFERENCES}

1. Solow B, Tallgren A. Head posture and craniofacial morphology. Am J Phys Anthrop 1976;44:417-436.

2. Kylamarkula S, Huggare J. Head posture and morphology of the first cervical vertebra. Eur J Orthod 1985;7:151-156. 
3. Watanabe M, Testsutaro Y, Koutaro M. Cervical vertebra morphology in different skeletal classes: a three-dimensional computed tomography evaluation. Angle Orthod 2010; 80(4):719-724.

4. Sonnesen L. Associations between the cervical vertebral column and craniofacial morphology. Int J Dent 2010;10:1-6.

5. Lamparski DG. Skeletal age assessment utilizing cervical vertebrae. Am J Orthod 1975;67(4):458-459.

6. Huggare J. Craniocervical junction as a focus for craniofacial growth studies. Acta Odont Scand 1995;53:186-191.

7. Atıroglu FS. Comparative data on facial morphology and muscle thickness using ultrasonography. Europ J Orthod 2005;27:562-567.

8. Van Spronsen PH. A comparison of jaw muscle crosssections of long-face and normal adults. J Dent Res 1992;71(6): 1279-1285.

9. O'Reilly MT, Yanniello GJ. Mandibular growth changes and maturation of cervical vertebrae - a longitudinal cephalometric study. Angle Orthod 1988;58:179-184.
10. Jan $\mathrm{H}$. Association between morphology of the first cervical vertebra, head posture, and craniofacial structures. Eur J Orthod 1991;13(6):435-440.

11. Houston WJ. Mandibular growth rotations-their mechanisms and importance. Eur J Orthod 1988 Nov;10(4):369-373.

12. Solow B, Siersbaek-Nielsen S. Airway adequacy, head posture, and craniofacial morphology. Am J Phys Anthropol 1984;86:214-223.

13. Sonnesen L, Bakke M, Solow B. Temporomandibular disorders in relation to craniofacial dimensions, head posture and bite force in children selected for orthodontic treatment. Eur J Orthod 2001;23:179-192.

14. Huggare J. Population differences in the morphology of the first cervical vertebra. Am J Phys Anthropol 1992;88:197-201.

15. Bench RW. Growth of the cervical vertebrae as related to tongue, face, and denture behaviour. Am J Orthod 1963;49:183-214.

16. Karlsen AT. Association between facial height development and mandibular growth rotation in low and high MP-SN angle faces: a longitudinal study. Angle Orthod 1997;67:103-104. 